\title{
HIJA DE SU TIEMPO, HUÉRFANA DE REALIDAD
}

JUAN PABLO AGUILAR ANDRADE

Universidad San Francisco de Quito 
El 28 de abril de 1813 murió en prisión en Guayaquil Luis Quijano, quien fuera uno de los secretarios de la Junta formada en Quito en 1810; sus últimos días los dedicó a redactar un "Discurso sobre la insurrección de América". ${ }^{1}$ con el que según sus palabras pretendía "desengañar a los pueblos alucinados, descubriéndoles (...) lo fútil y engañoso de los motivos en que se funda el sistema revolucionario". ${ }^{2}$

La política nueva y superficial afirmaba Quijano- ha pretendido vanamente formar estados unidos de nuestras provincias divididas en intereses y opiniones, adoptando ciegamente el sistema federativo. Este bello ideal que tanto deslumbra y arrebata, sin consultar la capacidad moral y política de nuestros habitantes mezclados de tantas castas extrañas y separados en distintas condiciones $y$ sin atender a la variedad, de circunstancias en que nos hallamos los americanos españoles respecto de los angloamericanos. $^{3}$

Aunque sin duda el texto de Quijano es más un mea culpa y un llamado a detener el proceso independentista que un análisis sobre sistemas de gobierno o propuestas constitucionales, el párrafo arriba transcrito permite introducir el tema al que se refieren las siguientes páginas: el divorcio entre las ideas constitucionales y

1 En Pensamiento Ilustrado Ecuatoriano, Quito, Banco Central del Ecuador, Corporación Editora Nacional, 1981, pp. 409432.

2 Ibíd., p. 415.

${ }^{3}$ Ibíd., p. 424. la realidad en la que pretendieron aplicarse.

El ideal, dice Quijano, puede ser bello, deslumbrante y arrebatador, pero no consulta la capacidad moral y política del pueblo, ni atiende las particularidades y circunstancias propias de los "americanos españoles"; es ésta reflexión, me parece, la que permite entender las particularidades de nuestro primer constitucionalismo, particularidades que en mayor o menor medida se mantienen hasta el presente.

\section{I}

\section{HIJA DE SU TIEMPO}

Si la conmemoración del bicentenario del 10 de agosto de 1809, inicio del proceso independentista en el actual Ecuador, pasó prácticamente desapercibida, la de otro hecho fundamental, la aprobación de la Constitución del Estado de Quito, simplemente no existió.

No se trata, lamentablemente, de un olvido inusual. Nos encontramos, más bien, ante una constante, la de considerar que la primera fase de nuestra independencia culmina con la masacre del 2 de agosto de 1810, e ignorar la declaración de independencia del 11 de diciembre de 1811, la Constitución del 15 de febrero de 1812 , la defensa militar y la derrota final de las ocho provincias libres que conformaban el Estado de Quito, el 1 de diciembre de 1812.

Con esto se deja de lado un capítulo fundamental, no solo de nuestra historia, sino de la historia del constitucionalismo. 
Las constituciones que empiezan a dictarse en América a partir de 1811 son, junto con la Constitución de Cádiz del año siguiente, las primeras continuadoras de la nueva forma de entender la organización política, que se había expresado en las constituciones norteamericanas $y$ francesas, a fines del siglo XVIII.

En el caso de Quito, y como lo ha hecho notar ya Carlos Paladines, el acta con la que se estableció la Primer Junta Soberana, el 10 de agosto de 1809, puede considerarse como un documento constitucional. ${ }^{4} \mathrm{Y}$ sin duda es así si se toma en cuenta, no solo que uno de los protagonistas del hecho la bautizó como $\mathrm{tal}^{5}$, sino que el documento establece $\mathrm{y}$ organiza una nueva forma de gobierno $y$, sobre todo, traslada al pueblo una soberanía que hasta entonces se reconocía como un atributo del monarca.

La noción de pueblo soberano, la "voluntad del pueblo" a la que se refiere el acta del Cabildo Abierto del 16 de agosto de $1809^{6}$, son ideas centrales de la teoría política que se desarrolla a partir de la constitución de la primera Junta quiteña; y se trata de ideas que conectan a plenitud con el pensamiento más avanzado de ese tiempo. Como lo muestra con claridad Ekkehart Keeding, la influencia de la revolución

${ }^{4}$ Carlos Paladines, "Sentido y trayectoria del pensamiento ecuatoriano", Quito, Banco Central del Ecuador, 1990, pp. 85-86.

5 Manuel Rodríguez de Quiroga, "Defensa de Rodríguez de Quiroga", en Pensamiento Ilustrado Ecuatoriano, Quito, Banco Central del Ecuador, Corporación Editora Nacional, 1981 pp. 393- 407.

6 "Acta del Cabildo Abierto celebrado en Quito el 16 de agosto de 1809 en la sala capitular de San Agustín", en Alfredo Ponce Ribadeneira, Quito 1809-1812, Madrid, Talleres Tipográficos del Asilo de Huérfanos del Sagrado Corazón de Jesús, 1960, pp. 148149. norteamericana y de la ilustración inglesa y francesa, está presente en las cartas, alegatos, manifiestos y proclamas que producen los protagonistas de nuestra primera etapa independentista. ${ }^{7}$

Tal vez el mejor ejemplo de lo dicho sea el "Manifiesto del Pueblo de Quito", cuyo primer párrafo redacta Juan de Dios Morales, a imagen y semejanza de las frases iniciales de la declaración de independencia de los Estados Unidos.

Cuando en el curso de los acontecimientos humanos -dice esta última- se hace necesario para un pueblo disolver los vínculos políticos que le han ligado a otro (...) un justo respeto al juicio de la humanidad exige que declare las causas que I impulsaron a la separación". "Cuando un pueblo (...) muda el orden de un gobierno establecido por largo tiempo -dice el texto de Morales- (...) conviene a su dignidad manifestar al público sus móviles y la justicia de su causa.

El preámbulo de la Constitución quiteña de $1812,{ }^{8}$ el "Pacto Solemne de Sociedad y Unión entre las Provincias que forman el Estado de Quito", sintetiza con absoluta precisión las ideas centrales del nuevo pensamiento político: reconoce como punto de partida la existencia de derechos naturales concedidos por Dios a los hombres (libertad, seguridad y prosperidad) y fundamenta en ellos la existencia de una soberanía original, que retorna al pueblo "por las disposiciones de la Providencia Divina, y orden de los acontecimientos humanos", y la necesidad de que la asociación política tenga como

7 Ekkehart Keeding, Surge la nación. La ilustración en la Audiencia de Quito, Quito, Banco Central del Ecuador, 2005, pp. 617627.

${ }^{8}$ Se utiliza el texto publicado en Ramiro Borja y Borja, Derecho Constitucional Ecuatoriano, Quito, 1979, tomo IV. 
fin "la conservación de los sagrados derechos del hombre".

Miguel Rodríguez, autor del texto constitucional, no hace otra cosa que tomar nota del cambio radical que se ha producido desde que se aceptó la idea del ser humano dotado de derechos y de una soberanía que el monarca solo tiene por encargo de su pueblo. La invasión napoleónica a España y la prisión de Fernando VII, son los acontecimientos humanos que hacen que la soberanía retorne al pueblo, y que los representantes del Rey en América pierdan legitimidad ante la ausencia de quien les había entregado autoridad. La Constitución se dicta en ejercicio de esa soberanía y configura un gobierno representativo, sobre la base de la división de poderes.

Es del caso subrayar que tanto la Constitución del año 12 como el original texto del año 10 , coinciden en la propuesta de organización de la vida política, de acuerdo con el esquema ilustrado, que a la simplicidad de la organización absolutista opuso el complejo sistema de separación de poderes, distribución de competencias y diferenciación de funciones $y$ atributos, con el objeto de sustituir el poder individual y absoluto del monarca. Para nuestros ilustrados, el nuevo Estado de derecho y democrático, se presentaba como una de las grandes y definitivas invenciones de la humanidad, radicalmente vinculado al progreso y prosperidad de los pueblos, porque preservaba al individuo de la omnipotencia de la autoridad y de sus abusos, y expresaba la "voluntad general" a través de sus representantes. La Constitución se transformó así para la razón ilustrada, en un sol que desde su altura esclarecería las inteligencias y al irradiarlas con su luz las conduciría por el debido sendero. ${ }^{9}$

Derrotado y moribundo, Luis Quijano, firmante de la Constitución, no cree ya en esto y piensa que todo ha sido un gigantesco error, un "bello ideal que (...) deslumbra y arrebata", pero cuya aplicación práctica no trae el orden, sino el caos.

\section{II \\ HUÉRFANA DE REALIDAD}

La Constitución de 1812, dice Carlos Paladines, concreta en "un ideal más del movimiento ilustrado" pero,

lamentablemente fue flor de un día, sea por los acontecimientos políticos que se precipitaron de inmediato, sea porque los contenidos de este ideal: soberanía popular, igualdad de los ciudadanos, respeto a sus derechos $y$ libertades, división de poderes, etc., no dispusieron ni de las condiciones necesarias para su ejercicio, ni de la claridad operativa a fin de que al 'qué' expuesto en el texto constitucional le acompañase la presión del 'cómo' concretar dichos ideales. ${ }^{10}$

Me parece que todos estos factores son, en realidad, aspectos de un mismo todo: la Constitución no se aplica porque sus promotores son pronto derrotados, pero estos hechos se precipitan porque no hay condiciones para que el pensamiento más avanzado de la época eche raíces en este suelo, y es esa falta de condiciones la que explica, precisamente, la falta de "claridad operativa".

Una buena muestra de ello son dos dudas que sin duda se consideraban como

9 Carlos Paladines, op. cit., p. 88

10 Ídem. 
jurídicamente fundamentales en los primeros años de la Gran Colombia: ¿̇la Corte Superior del Centro puede comunicarse con los intendentes sólo por medio del Secretario o tiene que hacerlo el Presidente? ¿la Corte puede exigir información a la Contaduría o debe únicamente solicitarla? ${ }^{11}$

La importancia concedida a dos temas tan triviales, pone en evidencia que la sociedad surgida de la independencia seguía siendo, pese a las declaraciones republicanas de igualdad, una sociedad del privilegio, lejana al mundo de los seres humanos libres e iguales que exigía, para ponerse en práctica, el ideal político de un reducido grupo de ilustrados.

Aunque en realidad el tema es más complejo. En realidad no había, salvo en contados casos, un ideal político moderno enfrentado a las formas tradicionales de organización social, sino que uno y otras convivían en las mismas cabezas.

Eso es precisamente lo que se desprende de la afirmación de Manuel Lorenzo de Vidaurre, en el sentido de que "algunos aristócratas podían ser más adelantados en política que muchos plebeyos, siempre y cuando el cambio de régimen no implicase el fin de las jerarquías". ${ }^{12}$

En los documentos producidos por el proceso independentista, no solo aparecen el pueblo soberano, el gobierno representativo y la división de poderes; el privilegio y las jerarquías nos esperan también en muchos párrafos. El acta de

11 David Bushnell, El régimen de Santander en la Gran Colombia, Bogotá, El Ancora Editores, 1985, p. 56.

12 Marie-Danielle Demélas, La invención política, Lima, IFEA, IEP, 2003, p. 191. conformación del primer gobierno el 10 de agosto de 1809, deja en claro que "la Junta como representante del Monarca, tendrá el tratamiento de Majestad: su Presidente de Alteza Serenísima, y sus Vocales el de Excelencia, menos el Secretario Particular, a quien se le dará el de Señoría". Once años después, tratamientos y uniformes son temas importantes en la Constitución cuencana del 15 de noviembre de 1820 .

La independencia rompe los lazos con España, pero no cuestiona las jerarquías; asume las formas políticas más avanzadas de su tiempo, pero se cuida de mantener inalteradas las estructuras sociales basadas en el privilegio.

Fernando de Trazegnies ha calificado este proceso como "modernización tradicionalista", y lo caracteriza como la "recepción de un cierto número de elementos capitalistas, ligada a una profunda resistencia a todo cambio en la estratificación social: se quiere devenir capitalista, es decir, 'moderno', pero al mismo tiempo se quiere conservar las jerarquías sociales tradicionales". ${ }^{13}$

En el caso de la sociedad quiteña, las jerarquías son el reflejo de un sistema económico basado en la hacienda, y es a imagen y semejanza de esta última, que se construye en los hechos la sociedad política, con un gran patrón que reparte premios y castigos desde la cúspide, y múltiples patrones que reproducen el esquema en todos los pisos de la pirámide.

Los seres libres e iguales en derechos del ideal ilustrado viven encerrados en las

13 Fernando de Trazegnies, La idea de derecho en el Perú republicano del siglo XIX, Lima, Pontificia Universidad Católica del Perú, 1992, p. 30. 
páginas de los textos constitucionales; la sociedad realmente existente basa sus relaciones en los vínculos personales, en las jerarquías, los privilegios y el intercambio de favores.

El juego político es, por eso, un juego de todo o nada; se es patrón o beneficiario de los favores del patrón, o excluido que busca construir un patronazgo y una red de favores distinta sobre los escombros de la que nos ignora. No hay equilibrios ni debate democrático, sino la búsqueda de un patrón que pueda establecer un orden en el que me sienta cómodo.

Eso implica, obviamente, que la voluntad del patrón reemplaza a la regla de juego y al gobierno de la ley; las normas, a la larga, son las establecidas por esa voluntad y es a partir de ella que las leyes se interpretan o se ignoran.

El caudillo colocado sobre la norma, capaz de establecer lo que es bueno y lo que es malo para la sociedad, es la figura central de esta forma de entender la política; lo tiene muy claro el prototipo del caudillo ecuatoriano del siglo XX, José María Velasco Ibarra:

Si en un momento de aguda crisis para la vida de un pueblo se salva la ley con peligro para el país, o se salva el país con quebranto de la ley, hace muy bien quien salva al país y viola la ley. ${ }^{14}$

14 José María Velasco Ibarra, Conciencia o barbarie, Quito, Editora Moderna, 1937, p. 162.

\section{III}

\section{CONSTITUCIONES ¿PARA QUÉ?}

Luis Quijano murió convencido del fracaso del ideal ilustrado, bello pero inaplicable en una sociedad $\sin$ "capacidad moral y política" para ponerlo en práctica. ${ }^{15}$ Ese ideal, sin embargo, se mantuvo y estuvo en la base de la construcción de las nuevas repúblicas; todas ellas fundaron nuevos sistemas de gobierno, sobre la base de textos constitucionales que reconocían la soberanía del pueblo, dividían los poderes y establecían gobiernos representativos.

Que estas ideas se mantuvieran vivas en los textos constitucionales, sin embargo, no es sinónimo de su aceptación general ni, peor aún, de su aplicación práctica, y basta repasar las páginas de la historia para comprobar lo acertado de la afirmación de Friedrich Hassaurek, quien vivió en el Ecuador en la época garciana.

Lamento decir que esos países son repúblicas por nombre pero en realidad son despotismos. Sus constituciones son por lo general liberales, pero las leyes y las constituciones se hacen para ser desatendidas. Todas establecen el sistema de tres poderes gubernamentales coordinados, pero realmente sólo existe un poder - la voluntad del hombre que por el momento ha asegurado la obediencia de los soldados. ${ }^{16}$

¿Por qué, entonces, subsiste la idea de hacer constituciones? No se trata, sin duda, de una simple necedad; si las constituciones se hacen es porque son

${ }^{15}$ Luis Quijano, op. cit., p. 424.

${ }^{16}$ Friedrich Hassaurek, Cuatro años entre los ecuatorianos, Quito, Abya Yala, 1994, p. 245. 
necesarias, porque cumplen algún papel, aunque este no sea el que les asigna la teoría política que les dio origen.

Separados de la monarquía española, los nuevos estados debieron buscar una fuente de legitimidad propia y esta no podía ser otra que la que ponían a su disposición los ideales ilustrados: el consentimiento general del pueblo soberano, expresado en una Constitución que sirve así "más como símbolo de legitimidad política para el poder, que como norma fundante de las demás en el ordenamiento jurídico"17.

Para el caudillo, los textos constitucionales son el ropaje que le permite vestirse de consenso y mostrar su gobierno como querido por la sociedad y resultado del voto mayoritario del pueblo soberano; pero son, al mismo tiempo, la forma que cubre con el velo de la democracia y los derechos un actuar que sigue anclado en los privilegios y en la arbitrariedad del gobernante.

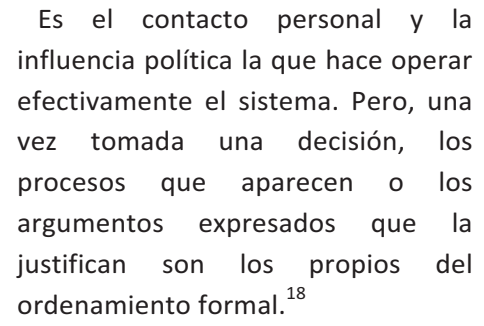

En otras palabras, las constituciones nacen huérfanas de realidad, pero pronto encuentran un lugar en esta última, no

17 Alberto Wray, "El sistema jurídico ecuatoriano", en Nueva historia del Ecuador, Quito, Corporación Editora Nacional, Grijalbo, 1995, tomo XIII, p. 186.

18 Rogelio Pérez Perdomo, El formalismo jurídico y sus funciones sociales en el siglo XIX venezolano, Caracas, Monte Ávila Editores, 1978, p. 99. porque empiece a operar el ideal ilustrado, sino porque éste se instrumentaliza para dar buena imagen al sistema $y$, en esa medida, mantener y consolidar la sociedad del privilegio.

El resultado acaba siendo el contrario del querido por Espejo, nuestro primer ilustrado, que descalificaba el absolutismo monárquico porque sacrificaba la sociedad a la vanidad de un solo individuo. ${ }^{19}$

19 Carlos Paladines, op. cit., p. 85. 


\section{BIBLIOGRAFÍA}

BORJA Y BORJA, Ramiro (1979). Derecho Constitucional Ecuatoriano, Quito, tomo IV.

BUSHNELL, David (1985). El régimen de Santander en la Gran Colombia, Bogotá, El Ancora Editores.

DEMÉLAS, Marie-Danielle (2003). La invención política, Lima, IFEA, IEP.

HASSAUREK, Friedrich (1994). Cuatro años entre los ecuatorianos, Quito, Abya Yala.

KEEDING, Ekkehart (2005). "Surge la nación. La ilustración en la Audiencia de Quito", Quito, Banco Central del Ecuador.

PALADINES, Carlos (1990). "Sentido y trayectoria del pensamiento ecuatoriano", Quito, Banco Central del Ecuador.

PÉREZ PERDOMO, Rogelio (1978). El formalismo jurídico y sus funciones sociales en el siglo XIX venezolano, Caracas, Monte Ávila Editores, p. 99.

VELASCO IBARRA, José María, (1937). Conciencia o barbarie, Quito, Editora Moderna.

TRAZEGNIES, Fernando de (1992). La idea de derecho en el Perú republicano del siglo XIX, Lima, Pontificia Universidad Católica del Perú.

WRAY, Alberto (1995). "El sistema jurídico ecuatoriano", en Nueva historia del Ecuador, Quito, Corporación Editora Nacional, Grijalbo, tomo XIII, p. 186. 